\title{
Intersystem Electron-Transfer in Di-hydrated Iodide Anion
}

\author{
Jung Mce Park* and Han Myoung Lec* \\ Department of Chemistry, Division of Molecular and Life Sciences, Pohang University of Science and Technology. \\ San 31, Hyoiadong. Namgu, Pohang 790-784, Korea \\ Received Mon 19, 2004
}

Key Words : Anion-water cluster, Charge-transfer-to-solvent (CTTS), Excess-electron water, Photo-induced electron-transfer, Quantum chemical ab initio study

The hydrated electrons of small size have been experimentally and theoretically investigated. ${ }^{1.0}$ The electronwater clusters can be prepared from neutral water vapor using low-energy electron beam and from charge transfer from anions. ${ }^{1-5}$ The hydrated anions with small numbers of waters have been studied through the experimental and theoretical tools for their structures, interaction energies, and spectra, especially for iodide among halide anions. ${ }^{(0) 17}$ These two categories are very close in view of chemical insight.

Many chemists reported the charge-transfer phenomena in hydrated halide anions using laser excitation. ${ }^{18.28}$ The excitation energies of hydrated anions were reported as the charge-transfer-to-solvent (CI'TS) energies. The hydration of electron from iodide-water clusters was studied by using the photo-excitation and the ultrafast dynamics using femtosecond time-resolved spectra. ${ }^{22}$ Molecular dynamics and simulation studies were performed for the hydration of electron from halide anions. ${ }^{2 .-25}$ The charge-transfer phenomena can be figured out in various chemical processes. ${ }^{20.27}$ Already we studied the CI"IS and CI"IS precursor states, iodine relaxation at excited state, rearrangement pathway to the lowest-energy electron-water pentamer and hexamer from the lowest-energy iodide-water pentamer and hexamer using high level $a b$ initio calculations. ${ }^{28}$

Here the CTTS process of iodide-water dimer and the hydration of excited excess electron $\left[1^{-} \mathrm{W}_{2}\left({ }^{1} \mathrm{P}_{1}\right) \rightarrow \mathrm{I}^{0}\left({ }^{2} \mathrm{P}_{3 / 2}\right)+\right.$ $\left.\mathrm{e}^{-} \mathrm{W}_{2}\left({ }^{2} \mathrm{~S}_{1 / 2}\right)\right]$ are studied by using $a b$ initio methods. This study is interesting and important in order to understand the formation mechanism and stabilization of electron-water dimer, the relationships between anion-water and electronwater dimer, and the electronic properties and phenomena of solvated or hydrated anions and electrons.

The structures of di-hydrated iodide ${ }^{17}$ and electron ${ }^{6}$ previously studied at B3LYP/6-3ll++G**. B3LYP/6-3I1++G** [sp] and MP2/aug-cc-pVDZ-(2s2p/2s) levels were adapted in this study. The extra diffuse functions in brackets and parentheses have the exponent values scaled by $1 / 8$ from those of the outermost basis functions in conventional basis sets. The CTTS energies of halide-water clusters were

\footnotetext{
"Corresponding Author, e-mail: abedolhm(a)postech.ac.kr

${ }^{t}$ Present address: Computational Science, Department of Chemistry and Applied Biosciences, FTH 7urich LSI Campus via Guiseppe Buffi 13, CH-6904 Lugano, Switzerland
}

predicted at the RPA-B3LY3/6-311+-G**, CIS/6-3II++ $\mathrm{G}^{* *}(\mathrm{sp})$ and $\mathrm{CIS} /$ aug-cc-pVDZ+(2s2p/2s) levels of theory. The IR spectra were calculated at $B 3 L Y I^{3} / 6-3 I I++G^{* *}(s p)$. $\mathrm{MP}^{2} / 6-3 \mathrm{Il}-+\mathrm{G}^{* *}(\mathrm{sp})$, CIS $6-31 \mathrm{l}++\mathrm{G}^{* *}(\mathrm{sp}), \mathrm{MP} 2 / \mathrm{aug}-\mathrm{cc}-$ $\mathrm{pVDZ}+(2 \mathrm{~s} 2 \mathrm{p} / 2 \mathrm{~s})$, and CIS/aug-cc-pVDZ $+(2 \mathrm{~s} 2 \mathrm{p} / 2 \mathrm{~s})$ levels of theory. All calculations were performed by using a Gaussian 03 suite of programs. ${ }^{29}$ Some important figures were plotted using the Pohang-']ech Molecular Modeling (POSMOL) package. ${ }^{70}$

Iodide-water dimer: 'The iodide-water clusters have been investigated and compared to the experimental results. ${ }^{1-17}$ The lowest-energy iodide-water dimer has $C_{1}$ symmetry and one water-water $\mathrm{H}$-bond interaction and two ion-water interactions as shown in Figure 1 . The iodide anion is surface-bound state with two water molecules. Its structure, energetics, spectroscopic data and electronic properties have already been discussed. ${ }^{14-17}$ Here we use its structure in order to understand the electron transfer and the formation of electron-water dimer.

CTTS of iodide-water dimer: The iodide-water dimer shows the iodine-released excited state from the vertical third singlet excited state at $\mathrm{MP}^{2} / 6-3 \mathrm{II}++\mathrm{G}^{* *}(\mathrm{sp}$ ) level (Figure 1). The B3LYP, MP2 and CIS calculations using 6$311+\mathrm{G}^{* *}(\mathrm{sp})$ basis set provide the transformation from Csil to $\mathrm{CsC}$ conformer, in which the latter conformer is known to be more stable than the former. However, the MP2 and CIS calculations using aug-cc-pVDZ- $(2 s 2 p / 2 s)$ basis set give slightly high-energy barrier between $\mathrm{CsT}$ and $\mathrm{CsC}$. conformers, due to the augmented and diffuse basis functions. The CIS/6-31I+- $\mathrm{G}^{* *}$ (sp) calculation can also provide the iodine-released structure with ${ }^{2} P_{1: 2}$. And then here, we report the CIS $6-311++\mathrm{G}^{* *}(\mathrm{sp})$ calculation results. Table I

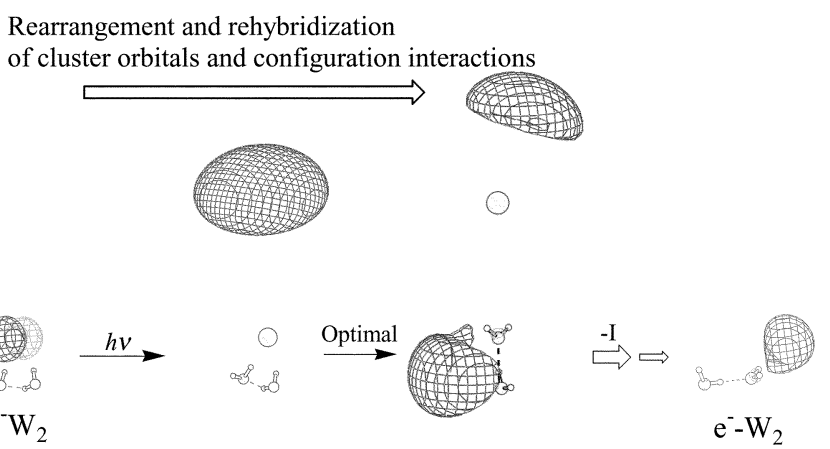

Figure 1. Prediction of CTTS process from iodide-water dimer. 


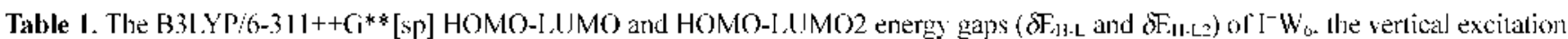
energies (CIJ'S) from the ground state. and the VI)I: of the CI'IS precursor states

\begin{tabular}{|c|c|c|c|c|c|c|c|c|}
\hline \multicolumn{2}{|c|}{ B3LYP } & \multicolumn{3}{|c|}{ CTTS } & \multicolumn{2}{|c|}{ CIS } & \multicolumn{2}{|c|}{$\mathrm{MP} 2$} \\
\hline$\partial \mathrm{E}_{\mathrm{II}-\mathrm{L}}$ & $\delta \mathrm{E}_{\mathrm{j}\} \cdot \mathrm{L}]}$ & RPA & $\mathrm{CIS}$ & MP2 & $\dot{\partial} g^{\prime}\left(S_{0}^{1: 3}\right)$ & $r^{O-1}\left(S^{1} \cdot i\right)$ & $\mu_{\text {treul }}$ & VDE \\
\hline 3.77 & 3.85 & 4.08 & $\begin{array}{l}4.37: 4.53^{6} \\
(3.93: 4.07)\end{array}$ & $\begin{array}{c}3.98 \\
(3.86)\end{array}$ & $\begin{array}{l}0.000 .0 .01 \\
0.33 \div 0.20\end{array}$ & $10.2: 8.3$ & 4.14 & 0.007 \\
\hline
\end{tabular}

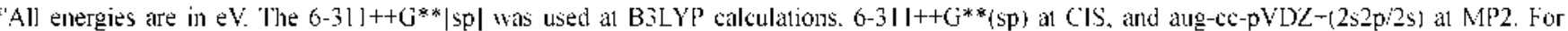

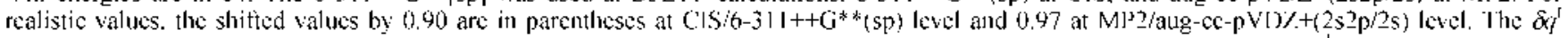
values in the first row are transferred charaes at vertical excited states and those in the second row at optimized excited states. "The second values for iodide-waler dimer at CIS are of the third CIS/6-3II $1 \cdot \mathrm{G}^{* *}(\mathrm{sp})$ excitation which has a virtual orbital for the charge transler. $\mathrm{r}^{(2-1}\left(\mathrm{S}^{1.3}\right)$ indicates minimal

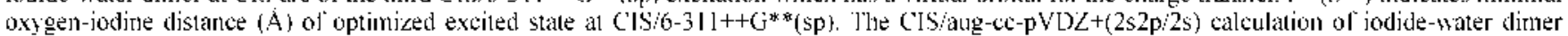
results in the cxcitation cnergies for $S_{1}: 4.32$. $S_{2}: 4.35 . S_{3}: 4.35, S_{4}: 4.35$ and $S_{5}: 4.35 \mathrm{cV}$.

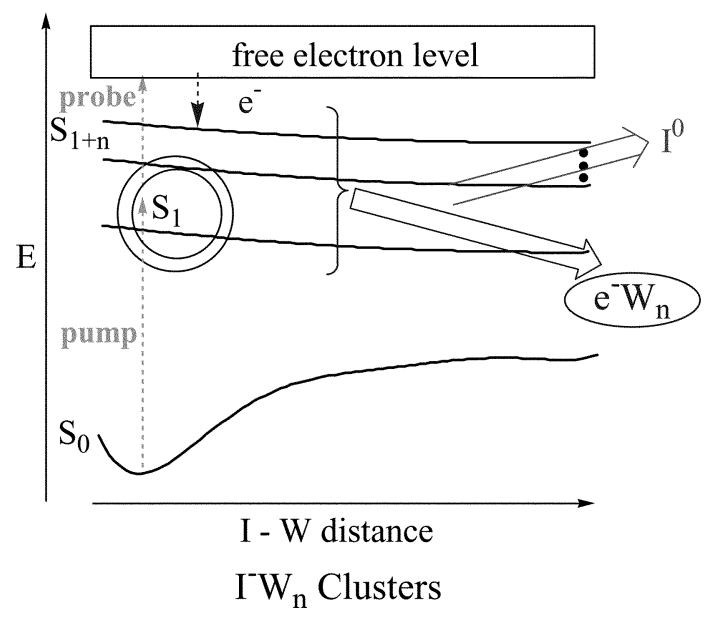

Figure 2. Potential-energy-surlaces (PI:Ss) for the release process of iodine atom at weited states of iodide-water clusters.

lists the excitation energies and interesting electronic properties of iodide-water dimer.

The brief CI"IS processes are drawn in Figure 2. Some excited states can easily decay due to the unfavorable electron-water binding states (Figure 2), which depend on the corresponding virtual orbitals and water structures for the excited electron. Experimentally, iodide-water pentamer and hexamer showed the kinetic energy changes from the excited states (CTTS states) due to the VDE variations, while iodide-water tetramer did not provide any kinetic energy change. ${ }^{22}$ In iodide-water dimer case, the VDEs of vertical and optimal excited states $\left({ }^{1} \mathrm{D}\right.$ or $\left.{ }^{2} \mathrm{P}_{3: 2}+{ }^{2} \mathrm{P}_{1: 2}\right)$ as the CTTS states are very low and similar to that of electronwater dimer. Then, the experimental and computational CTTS processes could give weak variations in the electron kinetic energy spectra. but the photo-induced charge transfer to water dimer complex could appear in iodide-water dimer due to the low-energy dihydrated electron. The excitation energies are close to the experimental data $(-3.9 \mathrm{eV})$ as listed in Table I."

The optimal distances between iodine atom and water dimer at the first and second singlet excited states at the CIS/ $6-311++\mathrm{G}^{* *}(\mathrm{sp})$ level are similar to that of ground state of iodide-water dimer within about $\mid \sim 2 \AA$ of the difference, while the iodine-water distance at the third singlet excited state is released upto about $8.3 \AA$. The rehybridization and rearrangement of cluster orbitals and configuration interactions were performed through the iodine release process. The optimized structures at excited states have nearly degenerate low-energy excited states for the singlet excitation, due to the nearly degenerate three $p$ orbitals of iodide anion. The first excited state releases the iodine at about 10 $\AA$, and the second excited state, at about $8.4 \AA$. The ' $\mathrm{P}$ $\left({ }^{2}{ }^{2}++^{2} S\right)$ state is higher excited state than the 'D states at vertical excited states, due to the hydration effect. The transferred charges are about 0.2-0.3 a.u. Through the intersystem crossing (ISC) process, the singlet excited state can be transformed into the triplet excited state with a hole and an electron of the opposite spin states, inducing more released structure.

Electron-water dimer: for the iodide-water hexamer. some rearrangement pathways to the lowest energy electronwater hexamer from the CI"IS state are essential, as noted in Neumark's experiments, ${ }^{22}$ while the electron water dimer (with s-like singly occupied cluster orbital; ${ }^{2} \mathrm{~S}_{1: 2}$ ) can be easily formed with iodine-detaching from the iodide-water dimer via a Cl'TS process, without any rearrangement pathway of water structure. The electron-water dimer is one of the magic numbers of excess electron-water clusters in mass spectra. ${ }^{1.5}$ The VDE observed was about $0.05 \mathrm{eV}$. In theoretical calculations, two possible isomers (CsC and CsT conformers) have been observed. The CsC conformer is more stable, with larger dipole moment and higher VDE. which is estimated to be close to the experimental value at MP2/aug-cc-pVDZ+(2s2p/2s). CCSD/MP2/aug-cc-pVDZ+ $(2 s 2 p / 2 s)$ levels and higher levels of theory."

IR spectra of di-hydrated iodide and electron: Figure 3 reports the IR spectra of the ground and excited states for iodide-water dimer, the electron-water dimer, and neutral water dimer at B3LYPi6-3। $1++\mathrm{G}^{* *}[\mathrm{sp}]$. MP2 $/ 6-31 \mathrm{l}++\mathrm{G}^{* *}$ (sp), and MP2/aug-cc-pVDZ+(2s2p/2s) levels of theory. These spectra were drawn using the shift values for the $\mathrm{OH}$ stretching modes of component water molecules with respect to the average value of asymmetric and symmetric $\mathrm{OH}$ stretching frequencies of pure water monomer, and the zero-shift value is compatible to the experimental average value $\left(-3700 \mathrm{~cm}^{-1}\right)$ for two stretching data $\left(v_{3}=3756\right.$ and $v_{1}$ $=3657 \mathrm{~cm}^{-1}$ ) of pure water monomer. ${ }^{31}$ The complexes provide the characteristic spectral changes for $\mathrm{OH}$ stretching modes through the photo-induced charge-transfer process. 


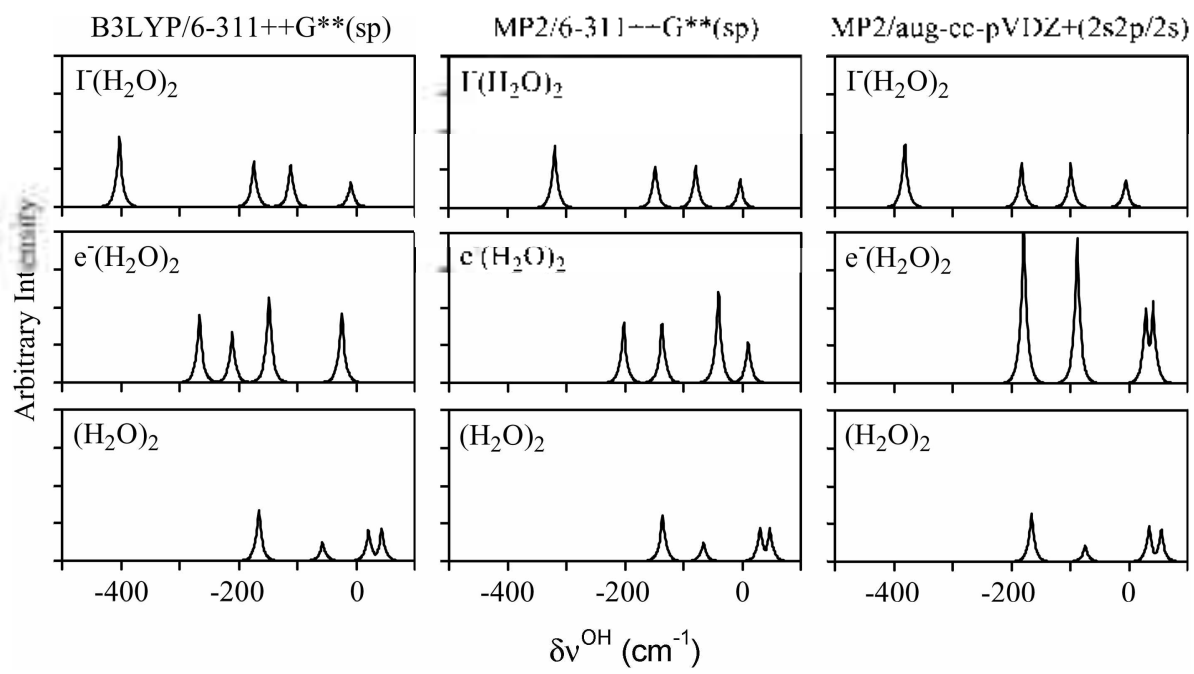

Figure 3. B3LYP/6-31I++ $\mathrm{G}^{* *}(\mathrm{sp})$ (in the first column). MP2(CIS)/6-3II+- $\mathrm{G}^{* *}(\mathrm{sp})$ (in the second column). and MP2/aug-ce$p V D Z+(2 s 2 p / 2 s)$ (in the third column) IR spectra of the ground and excited states of iodide-water dimer. electron-water dimer. and neutral wates dimer.

The excited iodide-water dimer and electron-water dimer show the intensive IR peaks due to flexible electron density. The red shifts depend on the strengths of ion-water, waterwater and electron-water interactions. The shifts of iodidewater dimer are higher due to strong ion-water interactions than those of electron-water dimer and neutral water dimer. The neutral water dimer has the smaller shifted spectra. The B3LYP/6-3I 1++G**(sp) IR spectra show higher shifted $\mathrm{OH}$ stretching frequencies with respect to the MP2 ones. The estimated IR spectra of iodide-water dimer are very close to the experimental results. ${ }^{14}$

In summary, using these quantum chemical calculations, the photo-induced electron-transfer of iodide-water dimer was investigated, and the spectroscopic characteristics from iodide-water dimer to electron-water dimer were understood through the C']'SS process. The water dimer clusters can be easily detected probabilistically. At the CTTS state, the neutral iodine atom was released, and excited electron was transferred to dipolarized water dimer. The water structure of excited iodide-water dimer is very similar to di-hydrated electron. The release of iodine atom at the excited state of iodide-water dimer from the ground state of iodide-water dimer could be expected to be exothermal process. This study could be useful to understand other photo-induced charge-transfer phenomena.

Acknowledgment. HMLee acknowledges the BK2I program for financial support.

\section{References}

1. Bowen. K. Il.: Ilaherland. H. Solvated Flectron chasters: Haberlaud. H. Lds: Springer-Verlag: 1995: Vol. II. Hydrated Hectron: Hart. E. J.: Anber. M.. Eds.: Wiley: Vew York. 1970. Electrons in Fhids: Jortner. J.: Kestner. N. R.. Eds.: Springer: Vew York. 1973

2. Desfrançois. C.: Carles S.: Schermann. J. P. Chem. Rew 2000.
100, 3943. Coc. J. V. In. Rev Phs Chen. 2001. 20, 33

3. Ambruster, M.: H laberland. [].: Schindler. I.-Ci. Pins. Rev Iett. 1981. 47, 323. Haberland. II.: Ludewigl. C.: Schindler. IL-Ci.: Worsnop. D. R. Siltf Sci. 1985. 156. 157. Desfrancois. C.: Khelifa. N.: Listi. A.: Schermann. J. P.: Eaton. J. G.: Bowen. K. H. f. Chem. Phos 1991. 95. 7760. Campagnola. P. J.: Cyr. D. M.: Johnson. M. A. Chent. Phis. Lett 1991. 18/. 206. Castleman. A. W.: Bowen. K. Il. J. Phs. (hem. 1996. I00. 12911.

4. (a) Coe. J. V.: I ee (i. [].: Laton, J. (i.: Amold. S. T.: Sarkas. II W.: Bowen. K. H.: Ludewigt. C.: Haberland. H.: Worsnop. D. R. . Chem. Phss. 1990. 92. 3980. (b) Lec. G. H.: Arnold. S. T.: Eaton. J. G.: Sarkas. H. W.: Bowen. K. H.: Ludewigt. C:: Haberland. H. Z. Phys D 1991. 20. 9. (c) Dustancois C.: Baillon, B.: Schemmamm. J. P.: Amold. S. T.: J Iendricks, J. H.: Bonvel. K. HI. Pins. Rev lett. 1994. 72. 48. (d) Kim. I.: I3ecker. L.: Cheshnowsky. O.: Johnson. M. A. Chem. Phys Lett. 1998. 297. 90. (e) Lee. G. H.: Arnold. S. T.: Eaton. I. G.: Bowen. K. H. Chem. Phos. Lett. 2000. 32/.333.

5. (a) Avotte. P.: Weddle. (i. II.: Bajles: C. (i.: Johnson, V. A.; Vila. li. Jordan. K. D. J. Chen. Phys 1999. 1/7. 6268. (b) Avolte. P.: Bailev. C. (i.: Kim. I. Jolunson. M. A. J. Chem. Phns. 1998. J08. 444. (c) Novahovskaya. Y. V.: Stepanow. N. F. (hem. Phs. Lett. 2001. 344.619

6. (a) Kim. J.: Lec. J. Y.: Oh. K. S.: Park. I. M.: Lec. S.: Kim. K. S. Phys. Rev \& 1999.59. R930, (b) Kim. J.: Sul, S. B.: Kim, K. S.J. (hem. Phys. 1999. /1/. 10077. (c) Kim. K. S.: Tarakeshwar. P.: l.e. J. Y. (hem. Rev 2000. I/) 4I45. (d) I.ee. II. M.: I ee. S.: Kim. K. S. J. (hem. Ihys. 2003. /19. 187. (e) Lee. H. M.: Sull. S. B.: Tarakcshwar. P.: Kim. K. S. JitCS. (submitted).

7. (a) Kim. K. S.: Park. I.: Lec. S.: Cho. K.: Lee. J. Y: Kim. J.: Joannopoulos J. D. Phs. Rev Lett 1996. 76,956. (b) Kim, K. S.; l.e. S.: Kim. J.: l.ee. I. Y. J Am. (hem Soe 1997. J19.9329. (c) I.ee. S.: Kim. J.: L.ee. S. J.: Kim. K. S. Phrs. Rev Lett. 1997. 79. 2038.

8. (a) Loc. H. M.: Suh. S. B.: Kim. K. S. Bull. Noreen Chem. Soc. 2000. 21. 555, (b) Loc. S.: Lee. H. M. Bull. Aorean Chem. Soc 2003.24.802

9. (a) Alonso. I). R.: Jordan. K. I) /. (hem. Phus. 2002. //6. 3612. (b) Vile I. D.: Jordan. K. I). J. Phos (hem .12002. 706. 1391. (c) Wang. F.: Jordan. K. D. J. ('hem. Phws. 20112. /16.6973.

10. (a) Arshadi. M.: Yamdagni. R.: Kebarlc. P. J. phys. Chen. 1970. 7f. 1475. (b) Hiraoka. K.: Misuze. S.: Yamalx. S. J. Plow. Chem. 1988. 02.3943 . 
11. (a) Markovich. G: Giniger R: Levin. M: Cheshnovsk: O. $J$. Chem. Phis. 1991. 95. 9416. (b) Markovich. G.: Pollack. S.: Giniger. R.: Cheshnovsky. O. J. Chem. Plws. 1994. 101.9344.

12. Bässmann. C.: Boesl. U.: Yang. D.: Drechsler. G.: Schlag. E. W. Int. J. Hass Spectront Ion Proc. 1996, 159, 153.

13. Achatz, U.: Joos, S: Berg. C: Beyer. M.: Neidner-Schatteburg. G.: Bondybey, V. E. Chem. Phs. Lett. 1998, 291.459.

I4. (a) Bailey. C. G.: Kim. J.: Dessent. C. E. H.: Johnson. M. A. Chem. Phys Lett 1997. 269. 122. (b) Ayotte. P.: Bailey. C. G.: Weddle. G. H.: Johnson. M. A. J. Phis. Chem. A 1998. 102. 3067. (c) Avotte. P: Weddle, G. H.: Johnson, M. A. J. Chem. Phns. 1999, 110,7129. (d) Avotte. P.: Weddle. G. H.: Kim. T.: Kelley. J.: Johnson. M. A. J. Plys. Chem. A 1999. 103. 4.43. (e) Ayotte. P: Nielsen. S. B.: Weddle. G. H.: Johnson. M. A.: Xantheas. S. S. $J$. Phys. Chem A 1999. 103. 10665. (t) Ayotte. P.: Weddle. G. H.: Kim. J.: Johnson. M. A. J. Am. Chen. Soc. 1998. 120. 12361. (g) Avotte, P.: Weddle. G. H: Kim, J.: Johntson, M. A. Chem. Phns. 1998, 239, 485

15. Johnson, M. S.: Kuwata, K. T.: Wong, C.-K.: Okumura, M. Chem. Phys. Lett. 1996. 260.551.

16. Dang. L. X. J. Chem. Phns. 1999. 110. 1526.

17. (a) Kim. J.: Lee. H. M.: Suh. S. B.: Majumdar. D.: Kim. K. S. J. Chem. Phns. 2000. 113, 5259. (b) Majumdar. D. Kim. I.: Kim. K. S. J. Chem. Plys $\mathbf{2 0 0 0}, 112,101$ (c) Lee. H. M.: Kim. K. S. J. Chem. Phys. 2001. 114. 4461.

18. (a) Combariza. J. E.: Kestner. N. R.: Jortner. J. J. Chem. Phys. 1994. 100. 2851. (b) Combariza. J. E.: Kestner. N. R.: Jortner. J. Chem. Phvs. Lett. 1993. 203. 423

19. Takahashi, N.: Sakai. K: Tanida, H.: Watanabe. I. Chem. Phns. Lett. 1995. 246. 183

20. Serxner D.: Dessent. C. E. H.; Johnson. M. A. J. Chem. Plys. 1996. 105.7231

21. Kloepter. J. A.: Vilchiz. V. H.: Lenchenkov. V. A.: Germaine. A. C.: Bradforth. S. E. J. Chem. Phvs. 2000. 113.6288.

22. (a) Lehr L.: Zanni. M. T.: Frischkon. C.: Weinkauf. R.: Neumark; D. M. Scrence 1999. 284. 635. (b) Davis, A. V.: Zan11i. M. T. Weinkaut. R.: Neumark: D. M. Chem. Ptns. Lett. 2002. 353.455.

23. (a) Borgis. D.: Staib. A. Chem. Plys. Lett. 1994. 230. 405. (b)
Staib. A.: Borgis, D. J. Chem. Phus. 1995, 103. 2642. (c) Borgis. D.: Staib. A. J. Chem. Phus. 1996. 104. 4776.

24. Tobias. D. T.: Jungwirth. P.: Parrinello. M. J. Chem. Phrs 2001. 11+. 7036 .

25. Timerghazin, Q. K.: Peslherbe, G. H. J. Am. Chent. Soc. 2003. 125.9904.

26. (a) Gladstone. S.: Laidler. K: Eyring. H. The Theory of Rate Processes: McGraw-Hill: New York. 1941. Kramers. H. A Phosica 1940. 7. 284. (b) Marcus. R. A.: Sutin. N. Biochint Biophts Acta 1985. 811. 265. (c) Tributsch. H.: Pohlmant1. L. Science 1998. 279, 1891, and references therein.

27. Page, C. C.: Moser, C. C.; Chen. X.: Dutton, L. Natwe 1999, 402. 47

28. Lee. H. M.: Suh. S. B.: Kim. K. S. J. Chem. Phus. 2003. 119. 7685

29. Frisch. M. J.: Trucks. G. W: Schlegel. H. B.: Scuseria. G. E: Robb. M. A.: Cheeseman. J. R: Montgomery. Jr. J. A.; Vreven. T.: Kudin. K. N.: Burant, J. C.: Millam, J. M: Iyengar. S. S: Tomasi, J.: Barone. V: Mennueci, B. Cossi, M.: Scalmani. G.; Rega. N.: Petersson. G. A.: Nakatsuji. H.: Hada. M.: Ehara. M.: Toyota. K.: Fukuda. R.: Hasegawa. T.: Ishida. M.: Nakajima. T.: Honda. Y:: Kitao. O.: Nakai. H.: Klene. M.: Li. X.: Knox. J. E.: Hratchian, H. P.; Cross, J. B.; Adamo. C.; Jaramillo. J.; Gomperts. R: Stratmann, R. E: Yazyev. O.: Austin. A. J.: Cammi, R: Pomelli. C: Ochterski. J. W. Avala. P. Y; Morokuma. K.: Voth. G. A.: Salvador. P.: Dannenberg. I. T.: Zakizewski. V. G.: Dapprich. S.: Daniels. A. D.: Strain. M. C.: Fartas. O.: Malick. D. K.: Rabuck. A. D.: Raghavachari. K.: Foresmant. T. B.: Ortiz. J. V: Cui. Q.: Baboul, A. G.; Clifford, S.; Cioslowski, J.: Stefanov. B. B.: Liu. G.: Liashenko. A.: Pistorz, P.; Komaromi, I.: Martin. R. L.: Fox, D. J: Keith, T.: Al-Laham, M. A.; Peng. C. Y: Nannayakiara. A.: Challacombe M.: Gill. P. M. W.: Johnson. B.: Chen. W.: Wong. M. W.: Gonzalez. C.: Pople. I. A. Ganssiam 03. Revision A.l ed.: Gaussian1. Inc.: Pittsburgh. PA. 2003.

30. Lee. S. J.: Kim. K. S. POSMOL. Reg. No. 2000-01-12-4239. Postech Licensing Center, Pohang. Korea, 2000. (Anonymous ftp address: ftp icsm50 postech ac.kr posmol)

31. Fraley. P. E.: Rao. K. N. J. 1 fol Spectrosc. 1969. 29.348. 